\title{
«LA COPA DEL REY DE THULE" DE FRANCISCO VILLAESPESA: MANIFIESTO POÉTICO DEL MODERNISMO ESPAÑOL
}

\author{
JosÉ ANDÚJAR ALMANSA
}

A Cristina, por el tiempo

Se acaba de cumplir el centenario de la publicación de La copa del rey de Thule, obra del poeta almeriense Francisco Villaespesa (1877-1936), cuya primera edición se imprimió en Madrid, en el otoño de 1900. El libro, un pequeño volumen de tan sólo quince composiciones y apenas sesenta páginas, constituye la primera muestra del modernismo poético en España, como se desprende de la temprana fecha de su aparición, precediendo ese mismo año a Ninfeas y Almas de violeta, de Juan Ramón Jiménez, y anterior a obras tan significativas del primer simbolismo como Alma (1902), de Manuel Machado, o Soledades (1903), de Antonio Machado. El éxito y la repercusión del libro, importantes, a tenor de la campaña de elogios y de ataques suscitada en torno suyo, así como el carácter de manifiesto que parece asumir en relación con la nueva corriente estética, son otros tantos argumentos que deberían servir para rescatar del olvido en que, con alguna notable excepción crítica ${ }^{1}$, se continúa relegando hoy día a Villaespesa, y reconsiderar, finalmente, el auténtico valor e in-

1 Son fundamentales en este sentido las aportaciones de Antonio SÁNCHEZ TRIGUEROS, quien sin duda es referente obligado en la recuperación crítica de Villaespesa; véanse sus estudios: Francisco Villaespesa y su primera obra poética (1897-1900) (1974); «La revista «Electra» (1901). Nuevos datos. Cartas de Villaespesa. Índice de autores» (1985); «Sobre el epistolario de Villaespesa a Sánchez Rodríguez (A propósito de una carta republicada)» (1988), y «Nuevas cartas de Villaespesa al poeta malagueño Sánchez Rodríguez y una lanza introductoria a su favor» (1993). Otras contribuciones de interés en estas dos últimas décadas han sido las de Ángela M. AMBrosinI, Fama $e$ marginalità di Francisco Villaespesa. Studio sull'ultimo modernista (1983); o bien las incluidas en el monográfico de la revista Las nuevas letras (1987), con colaboraciones de la propia AMBROSINI, "Aventuras y excesos modernistas de Francisco Villaespesa»; Ricardo GULLÓN, «Villaespesa abanderado del modernismo», y Richard CARDWELL, «El jardín finisecular: tres fuentes de Villaespesa». Más recientes son los trabajos de Marlene GoTTLIEB, Las revistas modernistas de Francisco Villaespesa (1995) y DÍAZ DE CASTRO, «Francisco Villaespesa y las poéticas del fin de siglo» (1998). 
terés que un título como La copa del rey de Thule encierra para el desarrollo de la poesía modernista en España.

\section{0: EL MODERNISMO Y LA GUERRA LITERARIA}

En los primeros años del siglo Villaespesa mantiene una intensa labor propagandística en favor de los nuevos gustos literarios, como demuestran los testimonios de los principales protagonistas de la época, Emilio Carrere, Juan Ramón Jiménez, Manuel Machado, Rafael Cansinos Assens o José Machado entre otros. «La casa de Villaespesa era el Ateneo de los modernistas», allí «nació y triunfó una escuela literaria» ${ }^{2}$, y Villaespesa fue el «paladín, el cruzado, el pújil del modernismo» ${ }^{3}$, su «muñidor más eficaz y su más típico representante» ${ }^{4}$, aquél que diera a conocer a tantos «la entrada del Reino Interior», convertido en «Hermes» principal de la nueva literatura ${ }^{5}$. Una nueva literatura cuyos principales valores serán «capitaneados» por el poeta, «que con generoso impulso y febril actividad, tanto se agitó en aquellos tiempos [...] de 'zafarrancho combate', impeliendo con su cálido entusiasmo a todos sus satélites» ${ }^{6}$.

Ese entusiasmo le lleva a relacionarse con multitud de poetas de Hispanoamérica, a traducir a escritores portugueses e italianos, a escribir innumerables prólogos y a ocuparse de la publicación de los libros de los amigos. Además, Villaespesa fundó algunas de las revistas más importantes del modernismo, casi siempre efímeras, pero con un valor estratégico como Electra (1901), Revista ibérica (1902), Renacimiento latino (1905) o Revista latina (1907-8) ${ }^{7}$, cubriendo así la necesidad de crear por parte de los modernistas, cuando aún no son aceptados por la cultura oficial, sus propios órganos de difusión.

2 Emilio CARRERE, «Vida y muerte de poeta», s/p.

3 Juan Ramón JIMÉNEZ, «Recuerdo al primer Villaespesa», p. 70. Artículo publicado originariamente en el diario $E l$ Sol, el 10 de mayo de 1936, a raíz de la muerte del almeriense.

4 Manuel MACHADO, «Madrid 1900: D. Francisco Villaespesa y el Modernismo», s/p.

5 Rafael CANSinos Assens, La nueva literatura. Los Hermes, I, p. 14. La primera edición de la obra es de 1917.

6 José MACHADO, Últimas soledades del poeta Antonio Machado, p. 42.

7 Del estudio de las revistas creadas por Villaespesa, cuya aparición antecedió en algunos casos a la de las grandes publicaciones del modernismo como Helios o Renacimiento, se ha ocupado recientemente M. GoTTLIEB: Las revistas modernistas de Francisco Villaespesa. Con anterioridad, SÁNCHEZ TRIGUEROS había publicado los índices completos de Electra: «La revista Electra...». Como estudio general sobre las revistas del período resulta imprescindible el libro de M. P. CELMA VALERo, Literatura y periodismo en las revistas del fin de siglo (1888-1907). Estudio e indice (1991). Merece también destacarse el artículo de Patricia MCDERMOTT, «Modernismo frente a Noventayocho: según las revistas de la época (1897-1907)» (1993). 
Cansinos Assens, sin duda el crítico más atento a la profusión renovadora de las nuevas escuelas, nos recuerda en sus imprescindibles memorias que todo el Madrid literario y artístico juvenil desfilaba por los sucesivos domicilios del poeta ${ }^{8}$, en la calle del Pez o Divino Pastor. Tal actividad convertirá a Villaespesa por espacio de un tiempo en el núcleo aglutinador de un grupo de jóvenes escritores con inquietudes artísticas renovadoras, entre los que se encuentran Juan Ramón Jiménez y los hermanos Machado (con quienes integra el llamado grupo de «los cuatro»), y otros como Isaac Muñoz, Antonio de Zayas, José Sánchez Rodríguez o José Durbán Orozco.

La influencia ejercida por el primer Villaespesa fue especialmente sensible en algunos de estos autores, como Manuel Machado, del que ya Gordon Brotherston señaló en su día las más que palpables deudas que el autor de Alma mantenía con el almeriense (106-10). Pero sobre todo será decisiva en el caso de Juan Ramón Jiménez, cuyo libro Ninfeas parece gestarse a la sombra de los poemas de La copa del rey de Thule, como nos recuerdan entre otros Palau de Nemes o Ángel González ${ }^{9}$. Por esos años la obra de ambos poetas andaluces, hoy definitivamente separada por el juicio crítico, parecía muy próxima en intención y carácter, implicadas como estaban las dos en una misma propuesta de novedad y renovación ${ }^{10}$. La historia además es de sobra conocida: un jovencísimo Juan Ramón Jiménez llega a Madrid tras recibir una postal firmada por Villaespesa y el mismísimo Rubén Darío invitándole a unírseles en la lucha por el modernismo. Se consolida así una estrecha amistad y hermandad literaria, de la que da noticia el propio Juan Ramón ${ }^{11}$, y que se inicia probablemente a raíz de las primeras colaboraciones del mogareño en la madrileña revista Vida nueva y del interés despertado por éstas entre algunos jóvenes renovadores. De Villaespesa Juan Ramón conoce entonces su libro Luchas (1899), enviado por el almeriense a quien ya considera su hermano poéti-

8 Rafael CANSINOS ASSENS, La novela de un literato, I, p. 149. Véase también Manuel MACHADO, «Madrid, 1900...», s/p., y Juan Ramón JIMÉNEZ, «Recuerdo al primer Villaespesa», p. 65.

9 Véase Graciela PAlAU DE NEMES, Vida y obra de Juan Ramón Jiménez, I, pp. 148-51, y Ángel GoNZÁLEZ, «Francisco Villaespesa en el primer centenario de su muerte. Posibles causas de un injusto olvido», p. 48.

10 Véase lo apuntado en este sentido, hace ya más de medio siglo, por José BERGAMíN en su artículo «Las telarañas del juicio. ¿Qué es poesía?» (1944).

1 Su memoria e impresiones de aquel tiempo las ha evocado Juan Ramón en las memorables páginas de «Recuerdo al primer Villaespesa», así como en «El modernismo poético en España e Hispanoamérica» (1982). Numerosos testimonios entresacamos también de los libros de Guerrero RuIZ, Juan Ramón de viva voz (1961) y Ricardo Gullón, Conversaciones con Juan Ramón (1958). Este último ha estudiado además el tema en «Relaciones literarias entre Juan Ramón y Villaespesa» (1959). Importantes datos ofrecen, por último, SÁNCHEZ TRIGUEROS en Francisco Villaespesa..., y PALAU DE NEMES en Vida y obra de Juan Ramón Jiménez, I, pp.130-57. 
co, y con toda probabilidad algún adelanto de La copa, cuyo ejemplar le dedicaría con las palabras: «Para mi único amigo, para mi único poeta/ Juan Ramón Jiménez, con el cariño entrañable/ de su hermano/ Paco» (Guerrero Ruiz, 191). De esta relación surgirá también el proyecto de la colección «Lux» de poesía, cuya importancia fue señalada en su momento por Sánchez Trigueros (Francisco Villaespesa..., 108-9), como un intento de crear un espacio editorial propicio para la difusión de los títulos modernistas de 1900, La copa del rey de Thule y Ninfeas ${ }^{12}$, a lo que debe añadirse el planteamiento de una estrategia literaria común, definida en los prólogos con que uno y otro autor reseñan la obra del amigo.

Precisamente un análisis detenido de estas cartas de presentación de los libros nos ilustra acerca de los temas que centran en ese momento el debate sobre la renovación de la lírica española y el papel que en ella deciden atribuirse ambos poetás. Así, en el «Atrio» escrito por Villaespesa para prologar el segundo de los libros publicados por Juan Ramón ese año de 1900, Almas de violeta, encontramos todas las ideas caracterizadoras del modernismo («conquista del ideal», «arte por el arte»), así como de la estética decadentista, comenzando por la imagen del poeta: «es un alma enferma de delicadezas; alma melancólica que, asomada a la ventana del Extasis, espera silenciosa la llegada de algo muy vago... El Amor..., La Gloria... Tal vez la Muerte» (Atrio, ii). Y junto a ésta, la visión de la mujer, con claras reminiscencias prerrafaelitas («musa bizantina, pálida y taciturna»), o la del paisaje, con ecos simbolistas («un sueño de Cisnes, en la calma religiosa del Crepúsculo»). Villaespesa entrevé a Juan Ramón como a un nuevo «Lohengrin», cuyos cisnes dirige hacia las «remotas playas de la Thule encantada». La imagen, como vemos, no puede condensar más quilates de modernismo: está el cisne, está Wagner, están las mitologías nórdicas, argumentos que en mayor o menor medida configuran toda esa primera etapa del modernismo español.

Pero el propósito fundamental, tanto del prólogo de Villaespesa como del de Juan Ramón, que se ocupa de La copa en un texto titulado «Elogio del poeta» ${ }^{13}$, era el de incidir en aquellos aspectos rupturistas e innovadores que servían para marcar las distancias respecto a las viejas poéticas decimonónicas. Por ello Juan Ramón encomia, por encima de todo, las

12 El hecho de que «Lux» se funde con la clara intención de situarse en la vanguardia del modernismo, explica el motivo por el que aparece fuera de colección el otro título publicado por Juan Ramón Jiménez en ese año, Almas de violeta, libro intimista y de mayor sencillez expresiva, y que se encuentra por ello mismo alejado de las audacias métricas, formales y tipográficas reservadas por su autor para Ninfeas como manifiesto de ese modernismo inicial.

${ }_{13}$ La reseña se publicó originariamente en 1900 con el título de «Triunfos: La copa del rey de Thule», en la revista malagueña Noche y día. Posteriormente se incorporaría como prólogo del libro a partir de su tercera edición en 1909. 
extravagancias expresivas que habían convertido a La copa del rey de Thule en un muestrario de irreverencias ante los ojos de la crítica:

Para mí, todas las frases y todas las palabras del libro de Villaespesa son perfectamente apropiadas; todas dan una sensación, y yo quiero antes sensaciones que fórmulas gramaticales, aun cuando para producir una sensación haya que metaforizar o simbolizar ideas de la manera más atrevida. («Elogio del poeta», 16-17).

Eso explicaría la insistencia, casi de manifiesto vanguardista, con que reclama Juan Ramón la necesidad de dejar atrás la imagen de un clasicismo estéril y monótono («¿A qué hacer en nuestro siglo la vida artística de los siglos muertos?»), anunciando por fin un progreso y una evolución largamente esperados en nuestras letrạs. Ese momento auroral, que Juan Ramón denomina la «Hora Rosa», tiene como protagonista indiscutible a Villaespesa, a quien el mogareño enfáticamente saluda como «primer poeta de nuestra juventud», y de cuyo triunfo, comparable al de «nuestros hermanos de América», no deja lugar a dudas:

Al fin un alma de oro lanzó el grito vibrante, el grito nuevo [...] La pobre Musa erudita de los buenos clásicos está de luto. («Elogio del poeta», 9)

La filiación con la poesía hispanoamericana resulta la mejor carta de presentación posible en ese momento. Juan Ramón, que tres años después iniciará a la poesía española en el camino del simbolismo francés, no cita en su prólogo a los poetas del Mercure, sino que centra toda su atención en la pléyade americana; esto es, en los nombres de referencia conocidos por Villaespesa, algunos incluso de la temprana época de composición de Luchas, y dados a conocer por éste a Juan Ramón durante su primera estancia en Madrid. Esto se confirma echando un vistazo a las dedicatorias de los poemas en La copa y Ninfeas, todas, al parecer, de la mano de Villaespesa, como recuerda el propio Juan Ramón ${ }^{14}$. Amigos, conocidos o interlocutores epistolares del almeriense, entre los que se encuentran Rubén Darío, Gómez Carrillo, Guillermo Valencia o Ricardo Jaimes Freyre, se homenajean en ambos libros (en realidad de las catorce dedicatorias que anotamos en la primera edición de La copa, doce se repiten en Ninfeas), lo que nos da idea no sólo del grado de intervención de Villaespesa en

14 Dice Juan Ramón: «cuando recibí la edición me encontré que Villaespesa había dedicado todos mis poemas a sus amigos y corresponsales hispanoamericanos, portugueses o filipinos, o yo no sé de dónde, pues a muchos de ellos yo no los conocía más que de oídas de Villaespesa» («Recuerdo al primer Villaespesa», p. 67). Y en otro lugar añade: «Villaespesa dedicó todos los poemas que yo no había dedicado en esos dos libros a escritores hispanoamericanos, y mandó las ediciones completas a América» («El modernismo poético...», p. 148) 
este asunto, sino también de la clara identificación de un grupo de escritores, más o menos afines, en los que se piensa como primeros destinatarios de la política poética de «Lux». Como señaló en su día Martínez Cachero a propósito de Ninfeas, la lista de nombres que encontramos en la mayoría de los poemas dedicados por Villaespesa y Juan Ramón nos pone sobre la pista de lo que podríamos calificar como «modernismo militante» («El juego de las dedicatorias...», 416), entre cuyas filas, además de los hispanoamericanos y los ya citados Sánchez Rodríguez, Durbán Orozco o los hermanos Machado, apuntan los nombres de Martínez Sierra, Francisco Aquino, González Anaya, Bernardo González de Cándamo, Julio Pellicer, Pedro González Blanco, Valle Inclán, Benavente o Nicolás María López. A éstos habría que añadir las referencias a poetas mayores en edad pero con reconocido prestigio innovador como Manuel Reina y Salvador Rueda, o críticos proclives 'como José Betancort. El hecho de que aquí aparezcan reunidos de la mano de Villaespesa la mayoría de autores que por esas fechas son simpatizantes del modernismo, responde a una campaña literaria que tiene como objetivo principal la definitiva puesta en escena de la nueva escuela, y que incluye, además de las dedicatorias, una labor de propaganda que se confía a los amigos, la solicitud de reseñas en determinadas revistas y periódicos, o la distribución de ejemplares en librerías y lugares diversos ${ }^{15}$.

Ese espíritu de manifiesto poético, que acompañará a La copa del rey de Thule desde el momento mismo de su aparición, queda patente al analizar el resto de críticas y reseñas favorables con que fue acogida entre sus partidarios. El propio Villaespesa recogería algunas de estas opiniones al publicar la tercera edición de la obra en 1909. Así vemos, por ejemplo, que un autor entonces consagrado como Manuel Reina aplaudirá el libro, asegurando que «marcará una nueva época en la poesía española, y es como la aurora de un espléndido porvenir literario» $(L C R T 3,177)^{16}$. El tono elogioso empleado por Reina indica la pauta seguida por el resto de opiniones sobre La copa, coincidentes en resaltar, más allá de sus excentricidades retóricas y sus innovaciones métricas y rítmicas, su condición de obra situada en la vanguardia de la moderna lírica, decidida a señalar «nuevos rumbos al pensamiento poético» $(L C R T 3,177)$, en palabras del crítico Pinto Ribeiro. Mientras que el también almeriense y poeta José Durbán afirma: «Yo creo que en esas poesías están los verdaderos gérmenes del arte moderno», capaces de abrir a los ojos del artista «horizontes hasta entonces

15 Véase SÁNCHEZ TRIGUEROS (Francisco Villaespesa..., pp. 235-44), quien nos ilustra, a través de la correspondencia mantenida entre Villaespesa y Sánchez Rodríguez, sobre los pormenores de esa campaña de difusión de La copa.

16 Véase «Opiniones sobre la primera edición de este libro», F. VILlaEsPESA, La copa del rey de Thule, Tercera edición «aumentada con varias composiciones» (1909), p. 177. En adelante citaremos como LCRT3. 
ignorados, medios de expresión y bellezas insospechables» (LCRT3, 178). $\mathrm{Y}$ en parecidos términos se decantan autores como Miguel Eduardo Pardo, Manuel Machado, Antonio de Zayas, Ricardo León, Julio Pellicer o Sánchez Rodríguez.

Lo cierto es que ningún otro título de Villaespesa atrajo tanto el entusiasmo de sus contemporáneos. Lo prueba el éxito del libro, que conoce una segunda edición antes de1902, como se deduce por la lista de libros publicados que su autor incluye en una obra de esa fecha ${ }^{17}$. Pero el interés despertado por La copa no estuvo exento de polémica, pues al reconocimiento y los apresurados elogios de sus compañeros de parnaso hay que sumar las más feroces críticas de sus detractores. Unos ataques que en realidad apuntaban sólo en parte al libro de Villaespesa, ya que tras la polémica sobre las excentricidades de su autor parece traslucirse la aceptación o el rechazo del modernismo, entendido por unos en el horizonte de 1900 como profunda renovación de nuestra lírica, y por otros, haciéndose eco por entonces de las tan extendidas ideas sociológicas de Max Nordau, como simple proceso degenerativo del arte.

En esa dirección se encontraban críticos como Tomás Carretero o Clarín, quien para entonces se había despachado ya desde las páginas de Madrid cómico contra el modernismo y los modernistas, a los que calificaría como «esa parte abortiva de la humanidad doliente» ${ }^{18}$. Tanto la reseña de Carretero sobre La copa del rey de Thule, publicada en Madrid cómico, el 26 de enero de 1901, como la de Clarín, aparecida póstuma el 7 de julio de ese año en Pluma y lápiz, fueron ya señaladas por Sánchez Trigueros (Francisco Villaespesa... 149-55), aclarando el carácter burlesco y la radicalidad de dichas críticas. A este tipo de manifestaciones antecedieron y siguieron otras con el mismo afán paródico y sarcástico hacia el modernismo desde periódicos y revistas como Gedeón, Blanco y Negro o Artes y Letras. En realidad era algo casi esperado, como advirtiera Juan Ramón Jiménez en el momento de presentar el libro:

Sobre el hermoso libro de Villaespesa, caerá una lluvia de insultos; la envidia hará de las suyas; los buenos clásicos lanzarán un anatema sobre el poeta, y a continuación de su nombre escribirán una lista interminable de adjetivos; lo llamarán decadente, lo llamarán simbolista. [...] La crítica rutinaria penetrará en el libro, a caza de imperfecciones que ridiculizar. («Elogio del poeta», 15).

Y no se equivocaba el amigo, pues pronto se consideraron risibles o peregrinas, por parte de la crítica más hostil, ciertas expresiones villaespe-

17 Esta segunda edición, que no hemos podido cotejar, y que debió ser una simple reimpresión sin más novedad (ya que es la tercera la que aparece aumentada), figura entre la relación de obras de su autor que se anuncian en El alto de los bohemios, publicado ese año de 1902.

18 Clarín, «Palique», Madrid cómico, 2 de junio de 1900, p. 278. 
sianas, como aquélla de «los murciélagos son sabios», que, al margen incluso de su autor, se convirtió en proverbial ejemplo de una sensibilidad «rara» y decadente, según nos recuerda, por ejemplo, Maeztu en 1901, cuando ironizando resume la receta de la «Poesía modernista»:

Se toman dos o tres centenares de palabras sencillas o raras - mejor raras, pero siempre sonoras-, y se las casa de dos en dos, procurando que el matrimonio sea entre cosas de distinta especie, ejemplos: sol auricadente, los violines magyares, aurorales ofelias, caricias de los astros, ¡Oh murciélagos sabios! ${ }^{19}$

Aunque más criticado que por sus mórbidos gustos lo fue el poeta almeriense por sus continuos deslices mitológicos, como nos recuerdan divertidos Cansinos Assens y Astrana Marín al aludir a aquella imagen de la «Esfinge», en el verso inicial de La copa, guardando silencio «con el dedo en el labio», o la confusión, ya en su libro siguiente El alto de los bohemios, de «Pan» con «Jano», al aplicar al primero el epíteto de dios «bifronte» en vez de «bicorne» ${ }^{20}$.

Pero Villaespesa no se amilanó jamás ante este tipo de críticas, consideró a la poesía desde muy temprano como una continua conquista del ideal, a la vez que una protesta contra la vulgaridad que lo circunda, un «esfuerzo inaudito de titán», donde «cada estrofa debe ser una pirámide, erigida con el trabajo hercúleo de toda una existencia sin reposo» (14-15), según leemos en Fiesta de poesía, una poética de 1912. En «Pasionaria», poema perteneciente a su libro anterior a La copa y de título tan significativo como Luchas, nos encontramos con esa imagen del poeta transfigurado en Cristo, arrastrando la pesada cruz de la incomprensión y la burla entre la plebe, con corona de espinas en vez de laureles ciñendo su frente, pero con inquebrantable fe en el poder redimidor de la poesía:

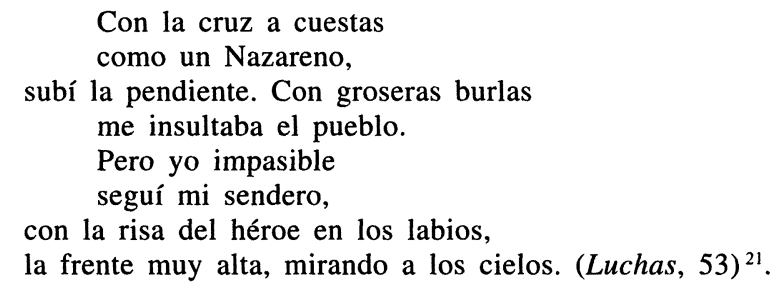

El poema está significativamente dedicado a Rubén Darío, abanderado de esa contienda artística que se libra ante los ataques más atrabiliarios de

19 Ramiro de MAEZTU, «Poesía modernista», p. 1.

20 Véase CANSINOS ASSENS, La nueva literatura... p. 78, y Luis ASTRANA MARÍn, «La obra de Villaespesa. Serie no interrumpida de plagios», p. 242.

${ }^{21}$ F. VillaespeSA, Luchas (1899), p. 53. La figura de Cristo es habitual en algunos poemas del período, donde llega a identificarse con un bohemio más. Véase Víctor FUENTES, Poesía bohemia española. Antología de temas y figuras (1999). 
la vieja crítica académica, y que Villaespesa traduce mediante la alegoría de un doloroso «calvario» ante el que, pese a todo, no se muestra dispuesto a sucumbir. La misma imagen se repite en «Adelante», texto también de Luchas:

\author{
No te canse lo largo del Calvario; \\ ni te arredren los golpes del dolor; \\ ipara que brote el fruto, es necesario, \\ que se agoste la flor! (Luchas, 44).
}

Frente a la actitud despreciativa de la mayoría, el arte nuevo pretende ser un arte de iniciados, de minoritarios cenáculos convertidos en templo, del que «látigo en mano», como nos sugiere el poeta, deben ser expulsados los eternos «mercaderes» que lo «profanan». El talante de ese compromiso estético quedaría reflejado en el «Atrio» escrito por Villaespesa para Almas de violeta, asumiendo allí esa condición de literatura militante que define a las poéticas del novecientos, en la que sus correligionarios aparecen como auténticos soldados de la belleza:

La mayoría de la Juventud, la Juventud batalladora y fecunda, se agrupa en torno de la nueva bandera, decidida a emprender denodadamente la conquista del «Ideal» [...] Su bandera, color de Aurora, ostenta esta leyenda, escrita con rosas frescas, con rosas de Primavera: «El Arte por el Arte». Y bajo este símbolo glorioso del Porvenir, las almas jóvenes y vigorosas se lanzan al combate, a rescatar el Viejo Templo y a arrojar de él, látigo en mano, a los mercaderes y saltimbanquis que lo profanan. («Atrio», i).

Se contagiaron de ese espíritu, no sólo Villaespesa, sino otros como Rubén Darío, quien en el célebre poema enviado a Juan Ramón para Ninfeas interroga al poeta andaluz en los siguientes términos: « ¿Tienes joven amigo, ceñida la coraza/ para empezar valiente la divina pelea?». En realidad el texto del nicaragüense viene precedido de otro similar escrito por él mismo en 1892 para honrar el pórtico de En tropel, libro de Salvador Rueda, a quien denomina «buen capitán de la lírica guerra,/ regio cruzado del reino del arte». Salvador Rueda debió tomar buena nota de estas palabras, pues en parecidos términos prologa a su vez el libro Luchas de Villaespesa, con un soneto titulado «Paladín»:

Es el Pegaso su corcel ardiente;

su fe y su juventud son su armadura,

va el verso, por espada, a su cintura

$\mathrm{y}$ es en su mano rayo incandescente.

Como gallardo paladín valiente

defiende la bondad y la hermosura,

y altiva muestra su gentil figura

por casco heroico, el arco de su frente. (Luchas, 19). 
No se alejan mucho de este tono otras declaraciones de la época; Manuel Machado acuñó el lema de la «guerra literaria», y pensemos, por ejemplo, en el manifiesto fundacional de Helios, en 1903, o en el prólogo hecho por Emilio Carrere para la primera antología del modernismo, La corte de los poetas, de $1906^{22}$. Aunque será Villaespesa, más que ningún otro, quien haga gala de ese carácter combativo, lo que lo convertirá en blanco predilecto de todo el antimodernismo beligerante.

\section{EL CANON MODERNISTA}

Pero ese afán propagandístico y divulgador, con ser importante, no es suficiente ni el único argumento para explicar la importancia de Villaespesa dentro de su horizonte literario. En cierta ocasión diría Melchor Fernández Almagro que «una manera de definir el modernismo es mostrar los libros de Francisco Villaespesa: los de su primera época» (173). Y es ahí sin duda donde radica el mayor acierto de sus títulos publicados por esas fechas, sobre todo de La copa del rey de Thule, convertido en surtido y deslumbrante escaparate de las diversas tendencias y formas del novecientos. En sus páginas se van a dar cita todos los elementos innovadores y extraños que caracterizarán la sensibilidad del fin de siglo. «O rinnovarsi o morire» había sido el lema d'annunziano grabado por el poeta en el frontispicio de su Copa. Y no le faltaron valor ni empuje a su autor para apostar por la implantación de una nueva lírica, que sitúa en esa tierra fabulosa y de ensueño de la mítica «Thule», límite del mundo conocido, como su leyenda indica, y punto de partida simbólico del libro.

«Enamorado de todas las formas y seguidor de todas las maneras», como había dicho de él Rubén Darío («Nuevos poetas de España», 419), Villaespesa apuesta por una estética distinta que lo aleje de la poesía tardorromántica de sus primeras obras escritas o publicadas por entonces (Intimidades y Flores de almendro [1898] y Confidencias [1899]), trocando así las vagas resonancias becquerianas por la búsqueda decadente de sensaciones y experiencias imaginativas, la melancolía por la expresión de la neurosis, y la nota sentimental por las contradicciones de un erotismo complejo y enigmático. Insólitas perspectivas líricas que dan paso a toda una poblada iconografía de cisnes, pavos reales, princesas góticas, wagnerianos Lohengrins,

22 El manifiesto de Helios, aparecido en su primer número de abril de 1903, dice entre otras cosas: «y henos aquí, paladines de nuestra muy amada Belleza, prontos a reñir cien batallas de verbo y de espíritu. ¡Guárdanos tú, la Dilectísima, por quien osamos entrar en lid!». E. Carrere, por su parte, en la «Nota preliminar» a La corte de los poetas, habla de un «grupo valeroso» a cuyo frente se encuentra Rubén Darío, «apóstol con un nuevo credo», y de una «cruzada del Ideal contra la mula burguesa» (Véase MARTíNEZ CACHERO, «Noticia de la primera antología del modernismo hispánico», p. 35). 
o místicos cruzados que transmutan la copa del rey de Thule en Santo Grial. $\mathrm{Y}$ junto a esto, las noches de Walpurgis, los murciélagos, las amadas difuntas, esfinges y femmes fatales, como fondo de un permanente desaliento espiritual, teñido de rebeldía y preocupaciones religiosas.

Esa exuberancia temática tiene su oportuno reflejo en el diverso muestrario de ritmos y metros, donde, junto a los sonetos dodecasílabos, alejandrinos y octonarios, encontramos combinaciones de versos polimétricos de veinte o más sílabas con otros de muy breve extensión, con los que el autor emula las innovaciones prosódicas de José Asunción Silva y Rubén Darío.

$\mathrm{Si}$ el flujo de las nuevas formas e ideas tiene su impulso sobre todo en la poesía hispanoamericana y en la lectura hecha allí del decadentismo y el simbolismo europeos, nadie de su tiempo estaría más atento que Villaespesa a cuantas novedades procedían del otro lado del Atlántico. De creer a Juan Ramón, tan próximo al poeta en esos años, el almeriense es el responsable de la introducción de muchas de esas novedades en España:

\footnotetext{
Villaespesa devoraba la literatura hispanoamericana, prosa y verso. No sé de dónde sacaba los libros. Es verdad que mantenía correspondencia con todos los poetas y prosistas hispanoamericanos, modernistas o no, porque para él lo de hispanoamericano era una garantía. Libros que entonces reputábamos joyas misteriosas y que en realidad eran y son libros de valor, unos más y otros menos, los tenía él, sólo él; Ritos, de Guillermo Valencia, Castalia bárbara, de Ricardo Jaimes Freyre, Cuentos de color, de Manuel Díaz Rodríguez, Los crepúsculos del jardín, de Leopoldo Lugones, Perlas negras, de Amado Nervo. («Recuerdo al primer Villaespesa», 70-71).
}

Los modelos importados por Villaespesa son, por tanto, de sobra conocidos. Comenzando por Rubén, cuya presencia tutelar se percibe a lo largo de la mayoría de poemas de La copa, aunque donde resulta más evidente es en los sonetos de tema mitológico. El vitalismo que anima a esos antiguos mitos, lo erótico como profunda armonía cósmica que trasciende en composiciones como «Pagana» y «La sonrisa del Fauno», o en otras un poco posteriores como «Pan», «Póstuma» o «La muerte del Sátiro», no pueden provenir sino de Darío. La Leda cantada por Villaespesa es la misma amante del dios transformado en cisne que glorifica el nicaragüense en un conocido soneto de Cantos de vida y esperanza. Las coincidencias son claramente apreciables: el lago y el paisaje en el crepúsculo, el acercamiento sinuoso del cisne, la posesión sexual de la doncella inadvertida; aunque las semejanzas más significativas las representan, por un lado, la metáfora que convierte el pico del ave en símbolo fálico; así en Rubén: «Y viola en las linfas sonoras a Leda,/ buscando su pico los labios en flor»; y en Villaespesa: 
Leda dio un grito, y se quedó extasiada...

$\mathrm{Y}$ el Cisne levantó rojo su pico

como triunfal insignia ensangrentada. $(L C R T, 43)^{23}$.

Por otro lado, vemos cómo el divino acto amoroso tiene su eco cordial, su sagrada resonancia en el eros vital de la naturaleza; en Rubén son los «turbados ojos de Pan», que chispean en el «fondo verdoso de fronda tupida», los testigos de aquel rapto de amor olímpico; en Villaespesa entonan su epitalamio «el ruiseñor entre el ramaje/ y un toro, ebrio de amor, muge salvaje/ en la sombra nupcial de la arboleda».

Pero no es sólo Rubén Darío; junto a la influencia de éste será decisiva la de José Asunción Silva, sobre todo de su célebre «Nocturno», evocado en alguno de los poemas más significativos de La copa, como «Los crepúsculos de sangre» o «Los murciélagos», en los que imita directamente la novedad métrica que supone la repetición de un pie rítmico con base tetrasilábica (ooóo). La importante presencia de Silva en Villaespesa (así como en otros autores del momento, caso del joven Juan Ramón) obedece, sin duda, al hecho de que en el colombiano, como también ocurre con el poeta español, subyacen, involucrados en una visión rítmica y temática innovadora, numerosos rasgos y elementos de fondo romántico, como son el tema de la joven mujer muerta, la noche, la melancolía, la angustia vital, y que resultan el contrapunto de ese mundo brillante de princesas, cisnes, jardines versallescos y luminosidad de los mitos helenos que constatamos en el Rubén de Prosas profanas.

Otro nombre a tener en cuenta en el libro de Villaespesa es el de Guillermo Valencia, a quien aparece dedicado el poema «Histérica», texto donde convergen varios de los motivos arquetípicos del decadentismo finisecular. Así, por ejemplo, la temática y el escenario: la Roma imperial en tiempos de Nerón, teatro de refinados vicios y crueldades, de martirios cristianos, orgías y cultos exóticos, que el propio Valencia había poetizado en composiciones como «El triunfo de Nerón» y «En el circo». En el poema de Villaespesa se añade además otro icono fin de siglo como es la imagen perversa y depravada de su protagonista: la «ardiente cortesana» exhausta de placeres, que en su búsqueda de nuevas y extrañas sensaciones, de goces caprichosos y antinaturales, se deleita con el espectáculo que le brinda el sacrificio humano, incluido el suyo propio:

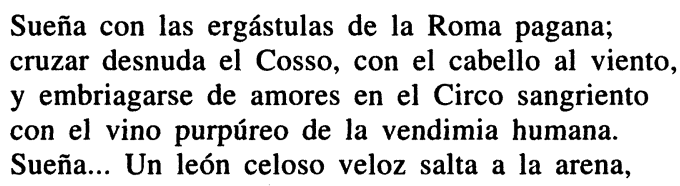

23 La copa del rey de Thule (1900), p. 49. De aquí en adelante nos referiremos a esta primera edición como LCRT. 
ensangrentando el oro de su rubia melena.

Abre las rojas fauces... A la bacante mira,

salta sobre sus pechos, a su cuerpo se abraza...

¡Y ella, mientras la fiera su carne despedaza,

los párpados entorna..., y sonriendo expira! (LCRT, 23)

Mención destacada merece, por último, el influjo ejercido por el boliviano Ricardo Jaimes Freyre y su libro Castalia bárbara. El cultivo exotista de una mitología nórdica o de temas medievales vinculados a ésta (como complemento a los de índole grecolatina y castellanista, más documentados en Darío) tuvo su repercusión inmediata en la poesía de Villaespesa, que los empleó desde el propio título de su libro. En efecto, las referencias a la mítica «Thule» (aparte de la deuda contraída con Goethe y señalada en su día por Sánchez Trigueros ${ }^{24}$ ) se registran en el poema «De la Thule lejana», de Jaimes Freyre, con idéntico epíteto usado luego por Villaespesa («la ideal paloma de una Thule lejana»). Lo mismo ocurre con el poema «Medieval», del español, que presenta sin duda parentesco con Rubén Darío, pero cuya atmósfera (de princesas, galantes torneos y caballeros wagnerianos) se adivina bastante cercana a las composiciones «Medioevales» del boliviano, entre las que se incluye también «El hermano pintor», con posterior reflejo en el final del poema «Silencio», de La copa. A veces incluso se constatan expresiones en Villaespesa que tienen su exacto precedente en Jaimes Freyre; así el verso «peregrinos que caminan por la noche de los hielos», del poema «Los cruzados de Thule», no es sino el eco de «el silencio indiferente de la noche de los hielos», que leemos en «El camino de los cisnes» de Castalia bárbara.

Además de estos, se perciben ecos de otros tantos autores, de Gutiérrez Nájera, de Amado Nervo, de Díaz Mirón o de Julián del Casal. Este caudal de lecturas no sólo se encuentra presente en La copa del rey de Thule, sino que a través de sus páginas se contagia a muchos escritores españoles del momento, dando así un impulso definitivo a la transmisión de las nuevas ideas líricas. Es por ello que debe considerarse al Villaespesa de $\mathrm{La}$ copa como al verdadero introductor de la poesía modernista en España, estableciendo de paso las necesarias distancias respecto a la obra de autores considerados precursores de dicho movimiento, como Manuel Reina, Ricardo Gil o Salvador Rueda. El hecho de que algunos elementos de la estética modernista y simbolista se adelantaran o intuyeran en obras como La vida inquieta o La caja de música, según nos recuerdan críticos como Díez Canedo, Luis Cernuda, o más recientemente Richard Cardwell ${ }^{25}$, no

${ }^{24}$ SÁNCHEZ TRIgueros nos remite a la «Balada del rey de Thule», cantada por Margarita en el Fáusto de Goethe, y a una dolora de Campoamor titulada precisamente «La copa del rey de Thule» (Francisco Villaespesa..., pp. 122-126).

${ }_{25}$ Véanse al respecto los trabajos de DíEZ CANEDO, «Los comienzos del modernismo en España» (1965); AgUlLAR PIÑAl, La obra poética de Manuel Reina (1968); Luis 
viene sino a incidir en la idea de que era posible encontrar en la tradición decimonónica española valores aislados asimilables a las nuevas tendencias, pero que la evolución final no pudo darse sin abrirse definitivamente la poesía española a las corrientes estéticas y de pensamiento que venían de Europa y de América.

El ejemplo más claro lo tenemos en Salvador Rueda, un poeta que, pese a su innegable protagonismo en la renovación formal y rítmica del momento, fue pronto relegado por los jóvenes modernistas. La razón se debe a que la poesía de Rueda no representó en el fondo una ruptura ideológica consciente con la cultura oficial, ni se desenvolvió en los ámbitos transgresores del amoralismo o del esteticismo como moral, ni cabe encontrar en ella, como nos recuerda Cardwell ${ }^{26}$, actitudes decadentistas o la expresión de conflictos nihilistas, religiosos o existenciales, todo lo cual en suma constituye el modernismo y la modernidad. Antes bien, la benevolencia y el paternalismo con que críticos como Valera o Clarín recibieron la poesía del malagueño, frente a la hostilidad demostrada hacia los primeros libros de Rubén, Villaespesa o Juan Ramón, nos habla a las claras de lo que la obra de uno y otros podía representar para las convicciones y creencias de la crítica conservadora. Como también nos induce a creer que es el afán de congraciarse con esta crítica - por la que se deja aconsejar- ${ }^{27}$ lo que explica el atrincheramiento en posiciones cada vez más casticistas y antimodernistas, cerradas a toda novedad externa, que se produce en el Rueda de principios de siglo.

La herencia de la tradición poética del XIX persistía también en la obra de Villaespesa, sobre todo expresada a través de la revitalización de un importante poso romántico subyacente en buena parte de los poetas de su generación, con sus manifestaciones esenciales de pesimismo esproncediano,

CERNUDA, «El modernismo y la generación del 98» (1975), y las ediciones críticas de Richard CARDWELL de La caja de música (1972), y La vida inquieta (1979); además de sus artículos, «Los albores del modernismo: ¿producto peninsular o trasplante trasatlántico?» (1985); «La política poética del premodernismo español» (1987), y «Ricardo Gil y el problema del origen español del modernismo» (1987). Un balance y estado de la cuestión de esta postura crítica se ofrece en el artículo de Manuel OTERO TORAL, «Estudio crítico y antología poética del primer modernismo español» (1986-87).

${ }^{26}$ Así lo afirma R. CARDWELL, para quien la religiosidad tradicional y convencional de Rueda dista mucho de los conflictos e inquietudes espirituales del modernismo («Rubén Darío y Salvador Rueda: dos versiones del modernismo» [1983]). Coincide con esta apreciación Guillermo CARNERO, que encuentra en el popularismo, la persistencia de una mitología rural, el filosofismo prosaico y la sensiblería no contenida - como características destacadas de los poemas de Rueda - serias limitaciones para su integración plena dentro del movimiento modernista ( $«$ Salvador Rueda: teoría y práctica del modernismo» [1987]).

27 Véase, respecto a este tema, MARTínEZ CACHERO, «La actitud antimodernista del crítico Clarín» (1983); así como lo apuntado por Cristóbal CuEvAS, «Modernismo: poéticas paralelas (La adscripción literaria de Salvador Rueda)» (1993). 
colorismo a lo Zorrilla, o bien el intimismo de Bécquer. Pero Villaespesa, al contrario de Salvador Rueda, supo además seguir muy de cerca modelos poéticos importados, expresando, a partir de éstos, no sólo ideas estéticas innovadoras, sino nuevas actitudes mentales que mostrarían a la poesía de su tiempo los futuros rumbos transitables.

\section{ÉPATER LE BOURGEOIS: DECADENTISMO E INMORALISMO}

Esa rebeldía estética que hallamos en las páginas de La copa del rey de Thule se convertirá, a su vez, en una decidida actitud de provocación moral. Si, como advierte Manuel Machado en La guerra literaria, se trataba de «exagerar determinadas tendencias para romper el hielo de la indiferencia general, irritar con algún desentono los oídos reacios y adoptar ciertas poses para llamar la atención» (106), nadie como Villaespesa pone tanto empeño en ese momento por escandalizar y alborotar el sosiego campoamoriano y decimonónico de la poesía patria. A Cansinos Assens debemos esa imagen del joven poeta como efigie misma de la provocación: «oficiando de raro, dejando crecer sus melenas y fumando cigarrillos egipcios, exponiendo peregrinas teorías sobre el matiz y la sensación» ( $L a$ nueva literatura, 76). Algo que ya había expresado en el "Atrio» escrito para Almas de violeta, aclarando que el arte nuevo debía ser «inmoral por naturaleza, místico por atavismo, y pagano por temperamento» («Atrio», i). No en el juicio ni en las intenciones, pero sí en el diagnóstico de los hechos coincidió Clarín con Villaespesa; esto es: el reconocimiento de la premeditada inmoralidad de mucha de la literatura modernista, a cuyos autores califica el crítico como «blasfemos fin de siglo» y propone incluso que sean perseguidos por la policía ${ }^{28}$. Antes aún que el almeriense, el asturiano había sentado como argumento contra la poesía moderna «la despreocupación moral y religiosa», propia de un «lirismo bueno para sementales», afirmando desde las páginas de La vida literaria en 1899: «No, no es una garantía de mérito artístico la ostentación de una juventud lasciva que no quiere ser casta... ni cauta» ${ }^{29}$. Claro que el dictamen sobre esa juventud, a la que también acusa Clarín de «convertir en musa la lujuria» ${ }^{30}$, no era interpretado de la misma manera por Villaespesa, para quien la inmoralidad de la poesía modernista debía traducirse en términos de una moral estética, pues lo sacrílego, lo erótico o lo morboso pretendían sacudir el buen juicio burgués en la misma medida que atentaban contra su gusto artístico las audacias métricas o expresivas de La copa.

28 ClARín, «Palique», Madrid cómico, 24 de febrero de 1900, p.166.

29 Clarín, «Mala maña», La vida literaria, 11 de febrero de 1899, pp. 98-99.

30 Clarín, «Palique», La vida literaria, 6 de julio de 1899, p. 417. 
El caudal más subversivo de esas innovaciones corrió de la mano del decadentismo, de donde recoge Villaespesa lo más impactante de su libro. La búsqueda continua de experiencias y de impresiones imaginativas que define el espíritu de esta escuela se traduce en la compleja sensibilidad y la hiperestesia nerviosa que respiran muchos poemas del período. No extraña que Manuel Machado calificara las Rimas de Juan Ramón como «libro femenino, histérico un poco» ${ }^{31}$, lo que nos hace recordar los «padecimientos» de su autor y sus sucesivas peregrinaciones por los sanatorios de Le Bouscat o del Rosario. Es el talante de la época, y como tal se deja sentir en Villaespesa, quien, para no ser menos que el poeta amigo, se jacta, con una pose muy fin de siglo, de que «hay días que me dan tres ataques de neurastenia» ${ }^{32}$. La inclinación hacia los dominios de lo mórbido y lo patológico, se convierte en curiosidad malsana de una «juventud viciosa y enferma», según declara elogiosamente Villaespesa ${ }^{33}$. Curiosidad que es a su vez búsqueda de un «algo más» que no satisface la prosa del mundo, y que los modernistas decadentistas hallan en los dominios de lo raro, la transgresión o la diferencia.

Un ejemplo de ello sería el recurso a un lenguaje poblado de referentes religiosos que, en combinación con otras realidades como el erotismo, lo macabro o el mal, acaba a menudo rozando lo blasfemo, según se aprecia en muchos pasajes de La copa del rey de Thule:

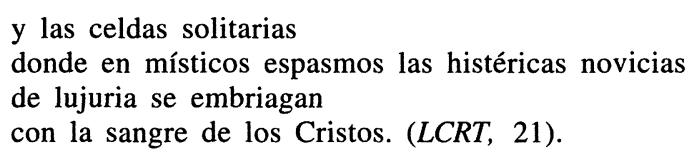

El texto pertenece a «Los crepúsculos de sangre», y es uno de los varios pasajes que podríamos citar en este sentido. Ahí están, si no, el último terceto de «Ave, Femina», despedido con la evocación de Magdalena por Cristo en el Calvario, o esa «hostia sagrada en el altar de Venus», del poema «Flores de ensueño», que recuerda a aquella otra «hostia de mi amorosa misa» de las Prosas profanas de Darío, con el desplazamiento

\footnotetext{
31 Véase Manuel MACHADO, Impresiones. El modernismo. Artículos, crónicas y reseñas (1899-1909), p. 296.

32 Véase R. FERNÁNDEZ SÁNCHEZ-AlARCOS, quien cita una carta del almeriense al poeta Sánchez Rodríguez en la que refiere la enfermedad nerviosa de Juan Ramón y la suya propia («Liberalismo y neurastenia: una carta de Villaespesa», p. 11).

${ }_{33}$ Lo comenta a propósito de Gómez Carrillo, presentando su retrato: «es el elegante croniqueur, el estilista brillante, el cuentista refinado y magnífico. Sus novelas parisienses son viciosas y enfermas como la juventud que las produce» (El Album de Madrid No. 8, 2 de junio de $1899, \mathrm{~s} / \mathrm{p}$ ). Aunque el texto aparece sin firma, tuvo que ser sin duda Villaespesa, miembro entonces del consejo de redacción de la revista, y el mejor conocedor en aquel momento de la joven literatura hispanoamericana, quien redactara el comentario sobre el escritor guatemalteco.
} 
del cuerpo místico de la eucaristía a la celebración del cuerpo de la mujer. Aunque todavía resulta más explícita esa imagen de una liturgia erótica en el poema « ¿Evohe!», incluido en la edición de 1909:

Yo fui tu sacerdote. El que ofició en la misa nupcial, en la roja misa de Iniciación, el que bebió en el cáliz de tu más loca risa toda la sangre virgen de tu fiel corazón. (LCRT3, 145)

Por la misma secuencia de ideas, la «copa» a que hace referencia el título de la obra se transforma en metáfora del libro mismo, y vendría, ofrendada desde su canto inicial («Ofrenda») por el Cristo-Poeta, a convertirse en la transposición simbólica del cáliz eucarístico; un cáliz, en cualquier caso, que resulta ambiguamente sacrílego, pues en él a la vez reposan «divinos amores» junto a «besos en noches de orgía», «ensueños azules» (pureza, idealidad) junto a «rojos delirios» (pasión, sensualidad).

Además de resultar una provocación explícita, esta voluntaria confusión de lo cristiano y lo profano, con la consiguiente iconografía que genera, traduce a su vez la dimensión idealista y sacralizadora que el modernismo en general otorga a las manifestaciones de lo poético en ese fin de siglo. Pienso que es dentro de este orden de cosas donde cobra auténtico sentido el término «místico», empleado con tanta profusión por los literatos del período. Misticismo como evasión y anhelo de espiritualidad, una postura o actitud que oponer a la mentalidad práctica y materialista burguesa. Recordemos, por ejemplo, el calificativo de «santa» aplicado por Ernesto Bark y otros a la bohemia, así llamada por su constante aspiración al reino sagrado del arte; o el hecho de que autores como Villaespesa o Juan Ramón armonicen la lectura de Nietzsche con la de Kempis. Y es que misticismo, vitalismo o nihilismo resultan, más que contrarios, expresiones distintas de una misma inquietud espiritual, de inconformidad moral y religiosa. El ensueño de ideal y las tentativas por conquistarlo, dando la batalla, como hemos visto, contra el utilitarismo y la mediocridad circundante, se encarnan en esas figuras villaespesianas del Cristo-Poeta, crucificado en el calvario de la incomprensión, o en la del monje-guerrero del poema «Los cruzados de Thule», caballeros cenobitas de ese reino de lo sublime e imaginario:

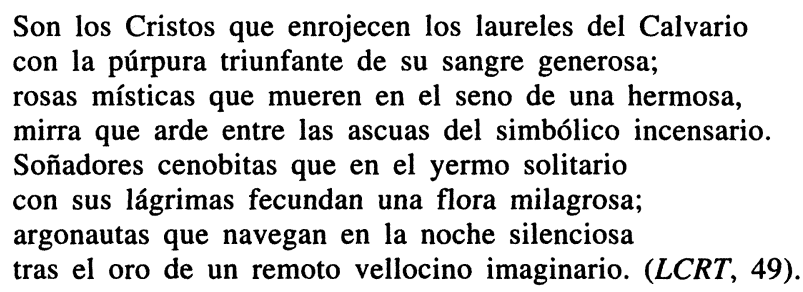


Pero lo místico tiende a menudo a confundirse, dentro de la literatura del período, en una atmósfera de refinada sensualidad, con la que contrastan las vagas aspiraciones de elevación espiritual o religiosa. Determinados aspectos del cristianismo, como el pecado, la tentación o el martirio se considerarán por ello mismo estéticamente aprovechables. Tenemos algún ejemplo en La copa, aunque es en «Cristiana», poema incluido en el libro posterior, El alto de los bohemios (1902), donde la temática resulta más recurrente:

\author{
Como en Jordán de gracia me he bañado \\ en tu santa palabra generosa, \\ y es gozo la tortura que hoy me acosa, \\ porque Vos, mi Señor, me la habéis dado. \\ A fuerza de cilicios he domado \\ la fiera de mi carne lujuriosa; \\ y hoy te ofrezco mi cuerpo, blanca rosa \\ que una lluvia de sangre ha salpicado! \\ Así clamó la tórtola divina. \\ Y mientras con la dura disciplina \\ los lirios de su carne maceraba, \\ la brisa del jardín traía aromas, \\ $y$ en la ventana abierta se arrullaba \\ una blanca pareja de palomas. $(A B, 53)^{34}$
}

Parece claro en este sentido que «rosa» o «lirio» funcionan aquí como simbología de la pasión, tanto en su vertiente religiosa como erótica, de la misma forma que la bíblica «paloma» se metamorfosea en imagen tentadora del deseo erótico frente a la casta determinación de la atribulada «tórtola». Añadamos además la expresión velada de un masoquismo que se complace en el martirio y la penitencia, el tono de ciertas manifestaciones («la fiera de mi carne lujuriosa») o la calculada ambigüedad de algunos versos («hoy te ofrezco mi cuerpo»), para inferir el funcionamiento de una técnica y unos motivos poéticos que se proponen la búsqueda de la intensidad estético-emocional a partir de la sugerencia y de una calculada dosis de escándalo y provocación.

$\mathrm{Y}$ es que el erotismo, como elemento desracionalizador y transgresor, será otra de las grandes bazas de los libros iniciales de Villaespesa. Un erotismo que es a la vez expresión de lo ideal y lo pecaminoso, de lo perverso y lo místico, de la carne y el espíritu, en clara simetría con los polos vitales y artísticos sobre los que transcurren sus poemas de esos años y con lo que representan las contradicciones propias de la modernidad desde Baudelaire. El placer físico se presenta a menudo como un interrogante abierto sobre el misterio esencial de la vida, a veces como antesala de la

${ }^{34}$ El alto de los bohemios (1902), p. 53. En adelante $A B$. 
muerte. La novedad en este caso no reside tanto en mostrar los aspectos más tangibles de lo erótico, algo que ya encontramos en ciertos escritos naturalistas del período, o en la poesía de Salvador Rueda, cuyas manifestaciones de la sexualidad y del amor físico en textos como «Himno a la carne» adoptan el aire de un vitalismo natural y espontáneo, muy distinto al de las refinadas morbideces modernistas. El propósito es descubrir las contradicciones de una sexualidad complicada, en la que el artista fin de siglo, como nos indica Lily Litvak, «descubre que Eros no sólo produce placer sino también soledad, desolación, desesperación, melancolía, spleen» (3), desembocando en la expresión dolorida de una angustia existencial. Por eso en algunos poemas de Villaespesa (al igual que en Rubén Darío, el joven Juan Ramón, Valle-Inclán, Verlaine o D’Annunzio) la tensión entre el anhelo de ideal y las tentaciones de la carne se traduce en la frustración melancólica de un conflicto espiritual nunca resuelto, pero también en una visión enigmática y contradictoria de lo femenino, expresado en dualidades como vida y muerte, atracción y perdición, ángel o demonio, y que se formula incluso en términos de un sincretismo cultural capaz de fundir la iconografía femenina cristiana con la pagana. Lo acertó a definir de manera rotunda Villaespesa en versos de El alto de los bohemios:

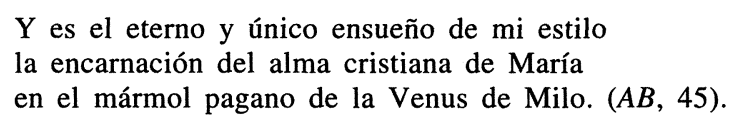

Pero es en «Ave, femina», sin duda uno de los textos fundamentales de La copa del rey de Thule, donde mejor ensaya su autor todas las complejidades de lo erótico. Su título rinde al mismo tiempo saludo y homenaje a la deidad femenina que personifican los distintos rostros de la pagana Afrodita, símbolo de la eterna atracción sexual, la hembra fatal y destructora que recordamos en Helena, la legendaria perfidia de Dalila, o la idealidad manchada de Magdalena y Margarita, iconos decadentistas de la tentación y el pecado, a la vez que prototipos de una femineidad capaz de elevarse y elevarnos hasta el reino de la belleza moral. Rostros todos que esbozan el perfil de un único rostro, las distintas encarnaciones del eterno femenino y del imperio de la seducción erótica sobre el hombre: la Margarita goetheana del ideal y de los «ensueños azules», frente a la Venus de los «rojos delirios» y «corazón de Furia» personificada en Helena y Dalila. Y como síntesis ideal de todas ellas, Magdalena: a medio camino entre las sublimaciones del espíritu y las tentaciones de la carne, entre pureza y sensualidad, entre la virgen y la prostituta ${ }^{35}$ :

35 Acerca de esta visión dialéctica de lo femenino dentro del decadentismo, véase el interesante trabajo de Javier HERRERO, «Fin de siglo y modernismo. La virgen y la hetaira» (1980). 


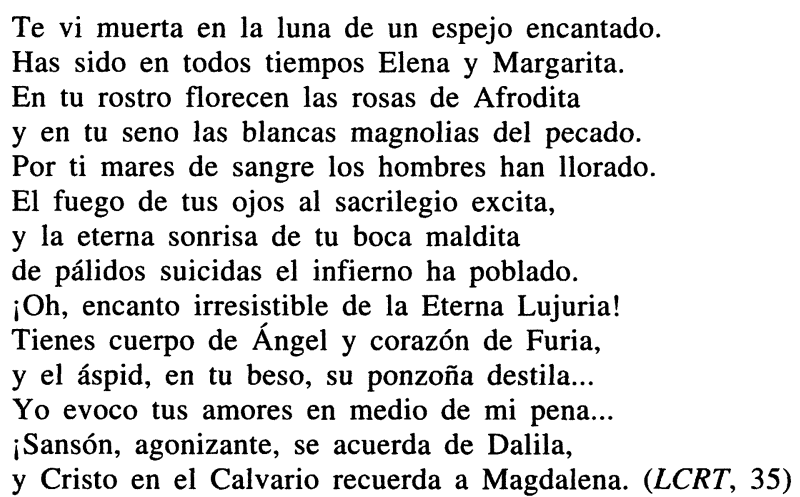

A estos nombres bastaría añadir el de Gioconda, cuya «eterna sonrisa» (cruel y eterna a su vez como la de la rubendariana marquesa Eulalia) se adivina en los versos del poema; y junto al de ésta, los de Salomé, Herodías, Circe, Judith y Cleopatra, si no presentes, presentidas en esa evocación de lo femenino, para obtener así un catálogo bastante representativo de la femme fatal decadentista y modernista, todas con una amplia representación literaria y pictórica en la época, como atestiguan los casos de Wilde, Gautier, D’Annunzio, Huysmans, Darío, Casal, Manuel Machado, o bien Moreau, Delville, Khnopff o Romero de Torres.

Cuando Villaespesa retome el tema en otro espléndido soneto, «Ensueño de opio», incluido en la tercera edición del libro, será para volver de nuevo sobre el retrato de la femme fatal y de todas las perversidades que la adornan: lujuria, ambigüedad sexual, sadismo, bestialismo, morfinomanía, pero mostrando esta vez sólo la cara de la «hetaira», de la «mujer-demonio» sin rostro de ángel y sin las contradicciones esenciales del prototipo anterior:

Sus rojos labios sáficos, sensitivos y ambiguos,

a la par piden besos de hombre y de mujer, sintiendo la nostalgia de los faunos antiguos, cuyos labios sabían alargar el placer.

Ama los goces sádicos. Se inyecta la morfina; pincha a su gata blanca. El éter la fascina, y el opio le produce un ensueño oriental...

De súbito, su cuerpo de amor vibra y se inflama

$\mathrm{Al}$ ver, entre los juncos, temblar como una llama

La lengua roja y móvil de algún tigre real. (LCRT3, 148).

Complemento y resumen a toda esta iconografía es la «Esfinge», cuya fabulosa condición al mismo tiempo de monstruo y mujer la convierte en símbolo de la propia ambigüedad femenina y de su profundo e inescrutable misterio: 


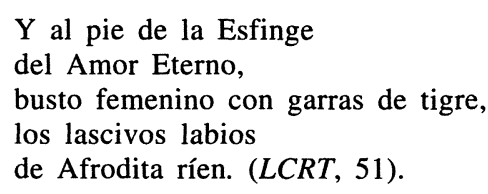

De nuevo la sonrisa, ahora en los labios de Afrodita, antes en los de Gioconda, como manifestación de un interrogante que vuelve a repetirse en el poema «La sonrisa del Fauno»: los nombres tienen aquí importancia sólo relativa, pues bajo ellos alienta la múltiple evocación de una sexualidad poderosa y selvática, pero también la formulación de lo erótico como ciclo antagónico o como enigma existencial:

— ¡Oh, púdicas vestales! ¡Oh locas meretrices!

¿Quiénes son más hermosas? ¿Quiénes son más felices?-

Los hombres preguntaron, en una edad lejana,

a un Fauno que en las frondas oculto sonreía..

Hace ya muchos siglos... $\mathrm{Y}$ en la conciencia humana

el Fauno a esa pregunta sonríe todavía. (LCRT, 53).

\section{EL ELEMENTO MACABRO Y LA HERENCIA ROMÁNTICA}

Otra manera de encarnar la transgresión en La copa del rey de Thule será a través de la efectista y sorprendente truculencia que hallamos en muchas de sus páginas. Baste citar entre ellas esa auténtica alegoría del horror que supone el poema «Los murciélagos», traducido en su día por el mismísimo D'Annunzio, y que resultó el texto más controvertido y criticado del libro, a la vez que el más emblemático:

Se alimentan con los lívidos gusanos que devoran a las vírgenes...

Se emborrachan con la sangre coagulada de los muertos [...]

$\mathrm{Y}$ en las hondas sepulturas

donde yacen enterrados mis recuerdos,

se enrojece vuestro hocico - vuestro hocico repugnante de vampiros-

con la sangre coagulada de mis muertos...

de las vírgenes difuntas que se pudren en sus tálamos de piedra

con las manos amarillas enlazadas sobre el pecho! (LCRT, 39-40).

Ejemplos de este calibre encontramos en algunos pasajes de «Los crepúsculos de sangre» o de «Parábolas», y abundan en otras composiciones de esa época, incluidas por el autor en la tercera edición de la obra, caso del poema "A Juan Ramón Jiménez», cuya imagen se asocia a un terrorífico bestiario: «las panteras de la fiebre devoraron tus entrañas;/ con la sangre de tus venas se han nutrido los murciélagos», y las hienas con los lomos erizados «han saciado sus feroces apetitos/ en la carne corrompida 
de tus muertos» (LCRT3, 171). Mientras que en «Spoliarium», de El alto de los bohemios, encontramos la visión de un árbol donde penden tambaleantes los ahorcados, rodeados de fetidez, «moscas de alas verdosas» y «diabólicos perros negros» que devoran sus despojos: «Los ahorcados tienen los rostros amoratados/ llenos de placas verdosas./ De sus amarillentos dientes/ cuelgan, sanguinolentas,/ sus hinchadas lenguas escamosas» $(A B, 77)$. Lo horrendo vale aquí también como creación de un clima, como escenificación equiparable a la de los suntuosos jardines adornados de estatuas mitológicas, pues ambas realidades resultan un desafío, una condena despreciativa contra las convenciones de la normalidad burguesa.

Nadie fue tan lejos en este sentido como Villaespesa; textos como los citados superan con creces en lo macabro y mórbido a los poemas más sombríos de Silva o a los posibles antecedentes españoles del momento. El hiperrefinamiento de las sensaciones, que había sido uno de los aspectos más destacables del decadentismo, logra transformarse en el Villaespesa de La copa en una morbosidad exacerbada, en una mezcla obsesiva de lo luctuoso y lo erótico sobre la que el poeta no volvería a insistir de manera tan rotunda en libros posteriores. Lo que demuestra que su empleo en 1900 obedece a un énfasis de provocación y novedad que lleva al autor a envolver su obra en destellos dispares de belleza, depravación, repugnancia y horror, elementos por igual subversivos con los que atraer hacia sí todas las miradas de la poesía de su tiempo. Tiene razón un crítico como Díaz de Castro, cuando afirma que la radicalidad de esos procedimientos en el libro de Villaespesa recuerda el gesto de los primeros movimientos de vanguardia, que llegarán una década después, y que pagarán con un olvido parecido esa búsqueda extrema de la sorpresa $(13)^{36}$.

En cualquier caso esas maneras tremendistas de Villaespesa fueron compartidas o contagiadas por entonces al joven Juan Ramón de Ninfeas, y las encontraremos poco después, orientadas hacia los aspectos más miserables, degradados y prosaicos de la realidad - lo que un crítico como Pedro J. de la Peña ha denominado el «feísmo modernista»- ${ }^{37}$ en autores como Emilio Carrere, Pedro de Répide, Pedro Luis de Gálvez o Agustín de Foxá. Ante ejemplos de este tipo, que cunden y que tienen en Villaespesa al primero de sus propagadores, no extraña que un conocido antimodernista de la época como Deleito y Piñuela clamara escandalizado desde las páginas de Gente vieja contra lo que consideraba, no sólo una degeneración del buen gusto y una «anestesia moral», sino el claro síntoma de un proceso disgregador de las sociedades modernas:

36 Véase también en este sentido lo apuntado por Luis Antonio DE VILLENA, para quien el «modernismo empezó siendo una vanguardia y lo guillotinaron otras vanguardias» («Fin de siglo: visión y terminología», p. 328).

37 Pedro J. DE LA PEÑA, El feísmo modernista. Antología (1989). 
Erotismos y obscenidades, delirios sangrientos y aterradoras quimeras, el satanismo, o culto sistemático al mal, la delectación morbosa con lo horripilante o corrompido; todo en los decadentes implica una anestesia moral, una emotividad desenfrenada, una exaltación neurótica y un desorden mental fronterizo en la locura ${ }^{38}$.

Invectivas aparte, lo cierto es que pesimismo e inmoralismo van juntos de la mano en el ánimo modernista y que ambos traducen el espíritu hastiado, torturado y meláncólico del fin de siglo, así como sus convulsiones ideológicas y religiosas. Si algo tienen en común los prólogos cruzados de Villaespesa y Juan Ramón Jiménez a sus libros de 1900, aparte de suponer una proclama del nuevo credo artístico, es esa creencia compartida de que el arte como proceso de elevación espiritual lleva aparejado el dolor. Si Villaespesa dirá del autor de Almas de violeta que es una «alma melancólica» y que «su poesía respira Dolor», mientras navega por un «lago de Sangre y Lágrimas» («Atrio», ii), Juan Ramón no le va a la zaga y en su comentario a La copa del rey de Thule nos describe a Villaespesa como al «cantor de la pena sangrienta y enlutada», y a su obra como un «cáliz de sangre y lágrimas» («Elogio del poeta», 12). Sobre la frente del poeta se ha posado, nos dice, «el fatídico beso negro», símbolo del dolor nostálgico y de la tristeza infinita, por eso su estrofa «es amarga como una adelfa, y roja como una lágrima crepuscular» («Elogio», 14). No fue sólo Juan Ramón, también José Bergamín evoca esa imagen de un Villaespesa «enlutado perpetuo, pomposamente funeral, borracho de todo lo oscuro, turbio $\mathrm{y}$ triste» (15).

Todo este pesimismo representa sin duda uno de los sentimientos originarios de la poesía moderna, herencia del romanticismo que adquiere con Baudelaire un sentido casi perverso de complacencia. Un espíritu tan fino como el de Juan Valera tenía necesariamente que advertirlo, y así se encarga de señalarlo en su célebre carta-reseña de $A z u l$, el libro fundacional de toda la modernidad poética en castellano. Si Valera observa que la poesía de Darío es como un himno que «a veces, en la mayor explosión de entusiasmo, el pesimismo viene a turbar con la disonancia, ya de un ay de dolor, ya de una carcajada sarcástica» $(A z u l, 112)$, es porque percibe en ésta claros indicios de un nihilismo que considera desestabilizador. En realidad la terrible conmoción espiritual que supuso el fin de siglo puede apreciarse y medirse en muchos de los temas y arquetipos poéticos del período, como la bohemia, el spleen, la soledad, la hipocondría, las violentas tensiones entre los anhelos idealistas y las sacudidas de la sensualidad, la frivolidad incluso o el sarcasmo más irreverente. Sin duda la mayoría de esas actitudes son rastreables en los primeros libros de Villaespesa,

38 Esta y otras opiniones del momento las recoge Jorge OLIVARES en su artículo «La recepción del decadentismo en Hispanoamérica» (1980). 
y no resulta una sorpresa encontrarnos con alguna declaración suya de signo abiertamente nihilista, como sucede en Fiesta de poesía, quizá la más reflexiva de sus poéticas:

El poeta moderno hace del dolor y del castigo un hondo y más nuevo motivo del canto, porque el dolor[...] es la raíz más profunda de la poesía[...] porque significa un conocimiento más perfecto de la vida y una sabiduría más experimental y amplia de los misterios del Destino[...] Por eso ni reza ni blasfema el poeta de hoy. Su vista ha penetrado las nieblas del Olimpo y ha hallado las cumbres vacías. Sus manos han palpado al Cristo agonizante sobre el ara, y le encontraron tan frío como el mármol en que está esculpido. Su razón se ha perdido en el laberinto de todas las teogonías, y ha vuelto de él, desengañada y aturdida, muerta para toda fe. (Fiesta de poesía, 19-20).

Creo que todo esto revela además otro hecho incuestionable, como es que, junto a la influencia decadentista, podamos hallar todavía un importante residuo de expresividad romántica en La copa del rey de Thule y en muchos de los libros primeros del modernismo español e hispanoamericano. Respecto a este último, recordemos que no faltó quien apuntara que el decadentismo de ultramar no fue sino un romanticismo exacerbado por las imaginaciones autóctonas (Olivares, 64). En el caso español, Cardwell ha intentado sondear el inequívoco fondo pesimista y las resonancias románticas sobre los que se erigieron las estéticas poéticas finiseculares («La obra poética de José Sánchez Rodríguez...», 29), y se refirió a sus principales cultivadores con la acepción de «románticos modernistas» («Ricardo Gil...», 231). Ahora bien, ese estigma romántico no reside tanto en el decorado de pesimismo y nihilismo, que, como hemos visto, parece constituir el paisaje de fondo de la lírica moderna, sino en el modo en que éste en ocasiones se expresa, inclinándose hacia un tono demasiado afectado y altisonante, demasiado profuso y decimonónico, como ocurre por momentos en la poesía de Villaespesa.

El tratamiento de algunos temas en La copa del rey de Thule (la muerte, el hastío, las ilusiones perdidas), nos remite a un desenlace que tiene que ver la mayoría de las veces con posturas vitales románticas (valgan como ejemplo los últimos versos del poema «Medieval», donde la calavera que asoma tras la armadura del caballero negro es un claro eco de El estudiante de Salamanca), por lo que la pose decadente resulta en estos casos algo ecléctica y amalgamada, sin los refinados matices que encontramos en obras paradigmáticas del género, como À rebours, de Huysmans, De sobremesa, de Asunción Silva, o incluso Prosas profanas, de Darío. Y es que no siempre acertó Villaespesa a expresar en los mismos moldes de estos autores todo ese mundo de sensaciones, de lo exótico o lo extraño, que venía con la novedad modernista, sino que se decantó a veces, en su afán por sorprender y enfatizar el ademán de ruptura, por la nota del tremendismo 
y lo macabro, prolongando con ello el eco de una poesía pesimista y dolorida que había sido la predominante en la centuria anterior.

\section{CONCLUSIÓN}

De una manera o de otra, el protagonismo de la poesía española en esas fechas iniciales del siglo pertenece ya para siempre a Villaespesa. Nadie como él en esos años de rebeldía artística, de fundación y de improvisaciones, desplegará una actividad tan intensa, convirtiéndose en el verdadero propagador del modernismo. Todo ese derroche de energías se traduce asimismo en su propia creación literaria. Villaespesa es autor de poemas «estratégicos» que por sí solos conforman una antología y un muestrario de todas las direcciones posibles del novecientos. Los diversos caminos, las diversas encrucijadas estéticas que configuran ese momento "de arranque de toda una nueva lírica tienen en La copa del rey de Thule su innegable punto de partida.

Pero a medida que este impulso renovador vaya consolidándose, irá tomando carta de naturaleza una poética más intimista y subjetiva, basada en el matiz y la sugerencia, una poética de tono menor que tiene su modelo no ya en los poetas hispanoamericanos, sino en el simbolismo de autores como Samain, Jammes, Verhaeren o Rodenbach entre otros. La importancia de esta corriente simbolista, que a partir sobre todo de 1903 constituirá la veta central y más valiosa dentro del modernismo en España, y el hecho de que en La copa del rey de Thule no se aprecien muchos rasgos de dicha escuela, en comparación con un mayor influjo del parnasianismo y el decadentismo, explicaría quizá la suerte contraria corrida por el libro de Villaespesa en relación con obras como Arias tristes, Soledades o La paz del sendero; títulos que imponen, frente a los tanteos primerizos, un gusto estabilizado y definido, y que acabarán relegando al olvido La copa del rey de Thule con todas sus importantes y decisivas aportaciones iniciales.

\section{BIBLIOGRAFÍA CITADA}

AgUilar PIÑAl, Francisco. La obra poética de Manuel Reina (Madrid: Editora Nacional, 1968).

Ambrosini, Ángela M. Fama e marginalità di Francisco Villaespesa. Studio sull'ultimo modernista (Perugia: Università di Perugia, 1983).

- «Aventuras y excesos modernistas de Francisco Villaespesa», Las nuevas letras, No.7 (1987), 13-22.

Astrana MARín, Luis «La obra de Villaespesa. Serie no interrumpida de plagios», Las profanaciones literarias. El libro de los plagios (Madrid: Biblioteca Ariel, 1920), 240-51. 
BERGAmín, José. «Las telarañas del juicio ¿Qué es poesía?», El hijo pródigo, vol. IV, No. 13 (1944), 11-20.

Brotherston, Gordon. Manuel Machado (Madrid: Taurus, 1976).

CANSINOS AssEns, Rafael. La novela de un literato, 3 vols. (Madrid: Alianza Editorial, 1995).

- La nueva literatura. Los Hermes. En Obra crítica, 2 vols. (Sevilla: Diputación Provincial, 1998).

CARDWELL, Richard A. (ed.). Ricardo GIL. La caja de música, Exeter Hispanic Texts III (Exeter: University of Exeter, 1972).

- (ed.). Manuel REINA, La vida inquieta, Exeter Hispanic Texts XX (Exeter: University of Exeter, 1979).

- «Rubén Darío y Salvador Rueda: dos versiones del modernismo», Revista de literatura, XLV, 89 (1983), 55-72.

- «Los albores del modernismo: ¿producto peninsular o trasplante trasatlántico?», Boletín de la Biblioteca Menéndez Pelayo, LXI (1985), 315-30.

— «La política poética del premodernismo español», Ínsula, 487 (1987), 23.

- «Ricardo Gil y el problema del origen español del modernismo», Actas del Congreso Internacional sobre el Modernismo Español e Hispanoamericano (Córdoba: Diputación Provincial, 1987), 219-37.

- «El jardín finisecular: tres fuentes de Villaespesa», Las nuevas letras, No. 7 (1987), 23-32.

- «La obra poética de José Sánchez Rodríguez en su contexto ideológico y literario». En José Sánchez Rodríguez, Alma andaluza (Poesías completas), ed. Antonio Sánchez Trigueros (Granada: Universidad de Granada, 1996), 15-89.

CARNERO, Guillermo. «Salvador Rueda: teoría y práctica del modernismo», Actas del Congreso Internacional sobre el Modernismo Español e Hispanoamericano (Córdoba: Diputación Provincial, 1987), 277-306.

CARRERE, Emilio. "Vida y muerte de poeta», $A B C, 11$ de abril de 1936.

CElma VAlero, María Pilar. Literatura y periodismo en las revistas del fin de siglo (1888-1907). Estudio e índice (Madrid: Júcar, 1991).

CERNUDA, Luis. «El modernismo y la generación del 98», Prosa completa (Barcelona: Barral Editores, 1975), 337-48.

CLARÍN, Leopoldo Alas. «Mala maña», La vida literaria, 11 de febrero de 1899, 98-99.

- «Palique», La vida literaria, 6 de julio de 1899, 417.

- «Palique», Madrid cómico, 24 de febrero de 1900, 166.

— «Palique», Madrid cómico, 2 de junio de 1900, 278.

Cuevas, Cristóbal. «Modernismo: poéticas paralelas (La adscripción literaria de Salvador Rueda)». En Pedro M. PIÑERo y Rogelio REYES, eds., Bohemia y literatura (Sevilla: Universidad de Sevilla, 1993), 111-31.

DARío, Rubén. «Nuevos poetas de España». En Obras completas, 4 vols. (Madrid: Afrodisio Aguado, 1950), I, 413-20.

- Azul y Cantos de vida y esperanza, ed. José María Martínez (Madrid: Cátedra, 1995).

DíAZ DE CASTRO, Francisco J. «Francisco Villaespesa y las poéticas del fin de siglo», Ínsula, 614 (1998), 12-14.

DíEZ CANEDo, Enrique. «Los comienzos del modernismo en España», Estudios de poesía española contemporánea (México: Joaquín Mortiz, 1965), 11-20.

FERNÁNDEZ ALMAGRO, Melchor. «El pobre Villaespesa», En torno al 98 (Madrid: Ediciones Jordán, 1948), 173-76.

FERNÁNDEZ SÁNCHEZ-ALARCOS, Raúl. «Liberalismo y neurastenia: una carta de Villaespesa», Ínsula, 493 (1987), 11. 
FuENTES, Víctor (ed.). Poesía bohemia española. Antología de temas y figuras (Madrid: Celeste Ediciones, 1999).

GoNZÁleZ, Ángel. «Francisco Villaespesa en el primer centenario de su muerte. Posibles causas de un injusto olvido», Triunfo, No. 778, 24 de diciembre de 1977, 46-48.

GotTliEb, Marlene. Las revistas modernistas de Francisco Villaespesa (Granada: Ediciones Anel, 1995)

GUERRERO RUIZ, Juan. Juan Ramón de viva voz (Madrid: Ínsula, 1961).

Gullón, Ricardo. Conversaciones con Juan Ramón (Madrid: Taurus, 1958).

- «Relaciones literarias entre Juan Ramón y Villaespesa», Ínsula, 149 (1959), 1 y 3

- «Villaespesa, abanderado del modernismo», Las nuevas letras, No. 7 (1987) 4-12.

HERRERO, Javier. «Fin de siglo y modernismo. La virgen y la hetaira», Revista iberoamericana, CX-CXI (1980), 29-50.

JIMÉNEZ, Juan Ramón. «Elogio del poeta». En F. Villaespesa, La copa del rey de Thule, Tercera edición, 1909, 9-17.

- «Recuerdo al primer Villaespesa», La corriente infinita. Crítica y evocación, ed. Francisco Garfias (Madrid: Águilar, 1961), 63-75.

- «El modernismo poético en España e Hispanoamérica», Política poética, ed. Germán Bleiberg (Madrid: Alianza Editorial, 1982), 137-54.

LITVAK, Lily. Erotismo fin de siglo (Barcelona: Antoni Bosch Editor, 1979).

MACHADO, José. Últimas soledades del poeta Antonio Machado (Soria: Imprenta Provincial, 1975).

MaCHADO, Manuel. «Madrid 1900: D. Francisco Villaespesa y el Modernismo», Legiones y Falanges: Revista mensual de Italia y España, No. 14, diciembre de 1941, $\mathrm{s} / \mathrm{p}$.

- La guerra literaria, ed. M.P. Celma y Francisco J. Blasco (Madrid: Narcea, 1981).

- Impresiones. El modernismo. Artículos, crónicas y reseñas (1899-1909), ed. Rafael Alarcón Sierra (Valencia: Pre-Textos, 2000).

MAEZTU, Ramiro de. «Poesía modernista», Los Lunes de El Imparcial, 14 de octubre de $1901,1$.

MARTÍNEZ CACHERo, José M. «Noticia de la primera antología del modernismo hispánico», Archivum, XXVI (1976), 33-42.

- «La actitud anti-modernista del crítico Clarín», Anales de literatura española, 2 (1983), 383-98.

- «El juego de las dedicatorias y el empleo de las mayúsculas en Ninfeas y Almas de violeta», Actas del Congreso Internacional Conmemorativo del Centenario de Juan Ramón Jiménez, 2 vols. (Huelva: Diputación Provincial, 1983), II, 413-22.

MCDERMOTT, Patricia. «Modernismo frente a Noventayocho: según las revistas de la época (1897-1907)». En Richard A. CARDWELl y Bernard MCGUIRK (eds.), ¿Qué es el modernismo? Nueva encuesta, nuevas lecturas (Boulder, Colorado: Society of Spanish and Spanish-American Studies, 1993) 229-55.

OLIVARES, Jorge. «La recepción del decadentismo en Hispanoamérica», Hispanic Review, XLVIII (1980), 57-76.

OTERO TORAL, Manuel. «Estudio crítico y antología poética del primer modernismo español». En Ayudas a la investigación, 5 vols. (Alicante: Instituto de Cultura Juan Gil Albert, 1986-87), V, 175-88.

PALAU DE NEMES, Graciela. Vida y obra de Juan Ramón Jiménez, 2 vols. (Madrid: Gredos, 1974).

PEÑA, Pedro J. de la. El feísmo modernista. Antología (Madrid: Hiperión, 1989).

SÁNCHEZ TRIGUEROS, Antonio. Francisco Villaespesa y su primera obra poética (18971900) (Granada: Universidad de Granada, 1974). 
- «La revista «Electra» (1901). Nuevos datos. Cartas de Villaespesa. Índice de autores». En Estudios románicos dedicados al Prof. Andrés Soria Ortega (Granada: Universidad de Granada, 1985), 631-647.

- «Sobre el epistolario de Villaespesa a Sánchez Rodríguez (A propósito de una carta republicada)», Ínsula, 498 (1988), 11-12.

- «Nuevas cartas de Villaespesa al poeta malagueño Sánchez Rodríguez y una lanza introductoria a su favor». En Antigva et Nova Romania (Estudios lingüísticos y filológicos en honor de José Mondéjar, 2 vols. (Granada: Universidad de Granada, 1993), II, 323-40.

VILlAESPESA, Francisco. Luchas (Madrid: Imprenta de C. Apaolaza, 1899).

- La copa del rey de Thule, Colección «Lux» de Poesía, I (Madrid: Establecimiento Tipográfico «El Trabajo», 1900)

- «Atrio» a Juan Ramón Jiménez, Almas de violeta (Madrid: Tipografía Moderna, 1900), I-III.

- El alto de los bohemios (Madrid: Imprenta de Ambrosio Pérez y Cia., 1902).

- La copa del rey de Thule, Tercera edición (Madrid: Librería de G. Pueyo, 1909).

- Fiesta de poesía (Madrid: Imprenta Helénica, 1912).

VILlENA, Luis A. de. «Fin de siglo: visión y terminología», La Torre, Año VI, No. 23 (1993), 315-31. 